\title{
Toward development of optical biosensors based on photoluminescence of TiO2 nanoparticles for the detection of Salmonella
}

Roman Viter, Alla Tereshchenko, Valentyn Smyntyna, J ulia Ogorodniichuk, Nickolay Starodub, Rositsa Yakimova, Volodymyr Khranovskyy and Arunas Ramanavicius

The self-archived postprint version of this journal article is available at Linköping University Institutional Repository (DiVA):

http:// urn.kb.se/ resolve?urn=urn:nbn:se:liu:diva- 140942

N.B.: When citing this work, cite the original publication.

Viter, R., Tereshchenko, A., Smyntyna, V., Ogorodniichuk, J., Starodub, N., Yakimova, R., Khranovskyy, V., Ramanavicius, A., (2017), Toward development of optical biosensors based on photoluminescence of TiO2 nanoparticles for the detection of Salmonella, Sensors and actuators. B, Chemical, 252, 95-102. https:// doi.org/ 10.1016/j.snb.2017.05.139

Original publication available at:

https:/ / doi.org/ 10.1016/j.snb.2017.05.139

Copyright: Elsevier

http:// www.elsevier.com/

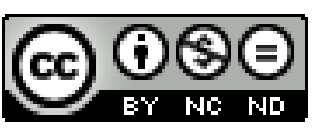




\section{Toward development of optical biosensors based on photoluminescence of $\mathrm{TiO}_{2}$ nanoparticles for the detection of Salmonella}

Roman Viter \#, Alla Tereshchenko \#*, Valentyn Smyntyna ${ }^{b}$, Julia Ogorodniichukc, Nickolay Starodub ${ }^{c}$, Rositsa Yakimova ${ }^{d}$,Volodymyr Khranovskyy ${ }^{d}$, Arunas Ramanavicius ${ }^{e}$

\# - authors equally contributed to this work

* - corresponding author

${ }^{a}$ Institute of Atomic Physics and Spectroscopy, University of Latvia, Rainis Blvd., LV-1586, Riga, Latvia

${ }^{\mathrm{b}}$ Experimental Physics Department, Odessa National I.I. Mechnikov University, 42, Pastera, 65026 Odessa, Ukraine

${ }^{\mathrm{c}}$ National University of Life and Environmental Sciences, 15, Geroyiv Oborony, Kyiv 03041, Ukraine

${ }^{\mathrm{d}}$ Department of Physics, Chemistry and Biology IFM, Linkoping University, 58183 Linkoping, Sweden

${ }^{e}$ Department of Physical Chemistry, Faculty of Chemistry and Geosciences, Vilnius University, Naugarduko str. 24, LT-03225 Vilnius, Lithuania

\section{Abstract}

Quality control of food and agriculture production is an inseparable part of human safety and well-being. Salmonella infections belong to one of the most monitored pathogens in the world, therefore advanced determination of this pathogen can decrease the risks of human diseases caused by this microorganism. In this research we introduce a novel optical immunosensor for determination of Salmonella typhimurium. The immunosensor is based on Titanium dioxide $\left(\mathrm{TiO}_{2}\right)$ nanoparticles deposited on glass substrates (glass $\left./ \mathrm{TiO}_{2}\right) \cdot \mathrm{TiO}_{2}$ nanoparticles exhibit an intense photoluminescence (PL) in the visible range of spectrum at room temperature. The direct immobilization of antibodies (anti-S-Ab) against Salmonella antigens on the surface of glass $/ \mathrm{TiO}_{2}$ has resulted in the formation of glass $/ \mathrm{TiO}_{2} /$ anti-S-Ab-based structure, which was characterized by increased PL intensity and IR-shifted position of the PL peak in comparison to the same characteristics of glass $/ \mathrm{TiO}_{2}$-based structure. The changes of the PL intensity and peak positions after interaction of the immobilized anti-S-Ab with Salmonella antigens (Salmonella$\mathrm{Ag}$ ) were used as immunosensor signal, allowing sensitive and selective detection of Salmonella$\mathrm{Ag}$ in a label-free configuration. The sensitivity of the reported optical immunosensor towards Salmonella-Ag is in the range from $10^{3}$ to $10^{5}$ cell $/ \mathrm{ml}$. Some aspects of the interaction between $\mathrm{TiO}_{2}$ and biological compounds have been discussed. This work opens up new possibilities for 
the development of optical label-free immunosensors suitable for fast, simple and efficient analysis of Salmonella infections.

Keywords: $\mathrm{TiO}_{2}$ nanoparticles, Photoluminescence based biosensor, Immunosensor, Salmonella infection, Antibody

\section{Introduction}

$\mathrm{TiO}_{2}$ is a well-known material, which was used for the application in different sensors and biosensors. $\mathrm{TiO}_{2}$ shows good stability in chemically aggressive environment what makes it an attractive material for sensors acting in such environments. $\mathrm{TiO}_{2}$ is a wide band gap semiconductor with indirect optical transitions . Quantum confinement effects in nanostructured $\mathrm{TiO}_{2}$ resulted in the increase of the band gap, the enhancement of photocatalytic activity and intense photoluminescence (PL) at room temperature .

A number of papers have reported the $\mathrm{PL}$ of $\mathrm{TiO}_{2}$-based nanostructures at room temperature . It was found that some $\mathrm{TiO}_{2}$-based nanostructures demonstrated emission in the range of 430-560 $\mathrm{nm}$. Two main mechanisms of $\mathrm{PL}$ for $\mathrm{TiO}_{2}$-based nanostructures were proposed: one is based on recombination of self trapped excitons (STE) $(430-530 \mathrm{~nm})$ and the other one is based on oxygen vacancies $(530-560 \mathrm{~nm})$. The recent papers on $\mathrm{PL}$ of $\mathrm{TiO}_{2}$ and the influence of dopants and type of nanostructure (nanotubes, nanosheets, etc.) point to a significant interest in this material and prospects of using $\mathrm{TiO}_{2} \mathrm{PL}$ in different sensors, especially in biosensors. $\mathrm{TiO}_{2}$ has low isoelectric point $\mathrm{pH}=5.5$ what is advantageous for protein immobilization on its surface . Due to this property the $\mathrm{TiO}_{2}$ was used in adsorbed enzyme based electrochemical biosensors .

Optical detection methods such as absorbance, reflectance and photoluminescence are suitable for simple, fast and accurate detection of target analytes . In the PL spectra of $\mathrm{TiO}_{2}$ were studied under different concentrations of $\mathrm{NO}_{2}$ at room temperatures in order to detect $\mathrm{NO}_{2}$ with $\mathrm{TiO}_{2}$-based optical gas sensor. An increase of the PL intensity was registered and no shift of PL peak position was observed. It was reported that $\mathrm{NO}_{2}$ adsorption on the sensor surface stimulated irradiative transitions in $\mathrm{TiO}_{2}$.

Quenching of the PL of $\mathrm{TiO}_{2}$-based quantum dots by BSA and DNA has been performed showing that the concentration of these biomolecules has strong influence on the decrease of PL intensity . In this case also no peak shifts were observed. This research illustrated that the PL of $\mathrm{TiO}_{2}$-based nanostructures could be applied for determination of various biomolecules (including 
DNA and proteins). $\mathrm{TiO}_{2}$ nanotubes were used for optical interferometry based label free sensing of rabbit immunoglobulin $\mathrm{G}(\mathrm{IgG})$. In this case a protein A capture probe was used, which was immobilized on the inner walls of $\mathrm{TiO}_{2}$ nanotubes by electrostatic adsorption. The selectivity of interaction was confirmed by experiments using IgG from poultry, which did not bind to protein A.

An immunosensor is a type of biosensors based on specific interaction between antibody $(\mathrm{Ab})-$ antigen $(\mathrm{Ag})$ immune complex . The $\mathrm{Ab}$ and $\mathrm{Ag}$ interaction is mostly very specific and sensitive towards some analytes what makes immunosensors suitable for accurate and precise tests with electrochemical, optical, magnetic and piezoelectric transducers . Some recent results show an efficient application of nanomaterials (e.g. nanoparticles and quantum dots) in biosensor platforms suitable for the detection of pathogens on the basis of surface plasmon resonance (SPR) and fluorescence based methods .

Food safety and agriculture are important fields of human activities . The quality control of food and agriculture production will decrease the risks of human diseases, caused by toxin infections. Salmonella typhimurium is one of the most monitored pathogens in EU . Some optical biosensors, based on SPR and reflectance spectroscopy, were developed for the detection of Salmonella at concentrations from $10^{2}$ to $10^{5}$ cells $/ \mathrm{ml}$.

In our previous papers we have shown the application of photoluminescent nanostructures for the design of immunosensor . In the present work we report the application of $\mathrm{TiO}_{2}$ nanoparticles in the design of PL-based immunosensor suitable for the detection of Salmonella.

\section{Experimental}

\section{Preparation of $\mathrm{TiO}_{2}-\mathrm{NP}$-modified samples}

Anatase nanoparticles with average size of $32 \mathrm{~nm}$, purchased from Sigma Aldrich, were dissolved in ethanol to obtain colloidal suspension with concentration of $0.05 \mathrm{mg} / \mathrm{ml}$. To improve homogeneity of the suspension, ultrasonic treatment and stirring were provided for 20 minutes. As a result, 'milky' suspension was prepared. Fifty microliters of the suspension were deposited on $\mathrm{Si}$ and glass substrates, dried and annealed in air atmosphere at $350^{\circ} \mathrm{C}$ for 2 hours.

\section{Structural and optical characterization of $\mathrm{TiO}_{2}-\mathrm{NP}$-modified samples}


Structural properties of $\mathrm{TiO}_{2}$ nanostructures deposited on glass (glass/ $/ \mathrm{TiO}_{2}$ ) were studied using Raman spectroscopy (Raman spectrometer with $\mathrm{Ar} / \mathrm{Kr}$ laser (Jobin Yvon- Labram 1B, $\lambda=647.1$ $\mathrm{nm}$, power $=100 \mathrm{~mW}$, power on the sample $9 \mathrm{~mW}$ ). Spectral resolution of $1 \mathrm{~cm}^{-1}$ was used for the registration of Raman spectra.

The surface morphology was studied by Asylum Research MFP-3D atomic force microscope, operating in tapping mode and equipped with a commercial silicon tip. The size of the AFM images was $4 \mu \mathrm{m} \times 4 \mu \mathrm{m}$.

Optical properties of glass $/ \mathrm{TiO}_{2}$ were investigated by PL. UV laser $(\lambda=266 \mathrm{~nm}$, power density $0.1 \mathrm{~W} / \mathrm{cm} 2$ ) was used to excite PL. PL registration was performed with a monochromator (Jobin Yvon - Spex HR 460) and a CCD detector (Jobin Yvon - Spex Spectrum-1, horizontal resolution of 2000 pixels).

\section{Preparation of biological samples}

Autoclaved culture of Salmonella typhimurium, which acted as antigen (Salmonella-Ag), obtained from the State Scientific-Research Control Institute of Veterinary Preparations and Feed Additives (Kiev, Ukraine) was dissolved in phosphate buffer saline (PBS), $\mathrm{pH}=7.4$, at concentration of $10^{9}$ cells per $1 \mathrm{ml}(\mathrm{cl} / \mathrm{ml})$. The initial solution of $\mathrm{Ag}$ was diluted by PBS, $\mathrm{pH}=7.4$, to get concentrations of $10,10^{2}, 10^{3}, 10^{4}, 10^{5}$ and $10^{6} \mathrm{cl} / \mathrm{ml}$. 'Anti-Salmonella serum', which contained antibodies $(\mathrm{Ab})$ against Salmonella (anti-S-Ab) was purchased from the St. Petersburg Research Institute of Vaccines and Serums (St. Petersburg, Russia) with initial concentration of $1 \mathrm{mg} / \mathrm{ml}$. The initial solution of $\mathrm{Ab}$ was diluted by PBS, $\mathrm{pH} 7.4$, at serum to PBS volume ratios of 1:200, 1:100, 1:50 and 1:10. Bovine serum albumine (BSA) was dissolved in PBS, $\mathrm{pH} 7.4$ at concentration $1 \mathrm{mg} / \mathrm{ml}$.

\section{Fabrication and evaluation of an immunosensor}

In order to determine the optimal concentration of anti-S-Ab to form glass $/ \mathrm{TiO}_{2} / \mathrm{anti}-\mathrm{S}-\mathrm{Ab}$ layered structure selective towards Salmonella, $5 \mu \mathrm{l}$ of solution was deposited on $\mathrm{TiO}_{2}$-modified surfaces from solutions with different concentrations of anti-S-Ab (diluted by PBS, $\mathrm{pH} 7.4$, at volume ratios 1:200, 1:100, 1:50 and 1:10) and incubated at room temperature for 20 minutes. Then the anti-S-Ab-modified glass/ $/ \mathrm{TiO}_{2} /$ anti-S-Ab surfaces were washed with $\mathrm{PBS}, \mathrm{pH} 7.4$ and gently dried with nitrogen flow. 
BSA was deposited from $5 \mu \mathrm{l}$ of $1 \mathrm{mg} / \mathrm{ml} \mathrm{BSA} \mathrm{solution} \mathrm{on} \mathrm{the} \mathrm{surface} \mathrm{of} \mathrm{glass/} / \mathrm{TiO}_{2} /$ anti$\mathrm{S}-\mathrm{Ab}$ to block free surface sites and to prevent glass/TiO $/$ anti-S-Ab structure from non-specific interaction.

The determination of Salmonella was performed by step by step addition of $5 \mu$ of Salmonella-Ag solutions with concentrations $10^{3}, 10^{4}, 10^{5}$ and $10^{6} \mathrm{cl} / \mathrm{ml}$. PL spectra were recorded after each modification and/or determination step.

\section{Results and Discussion}

\subsection{Structural and optical properties of $\mathrm{TiO}_{2}$ nanostructures}

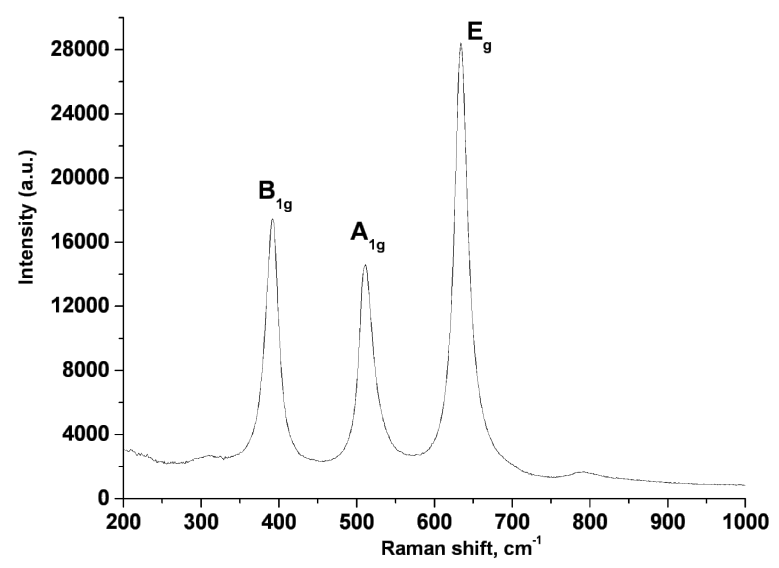

a)

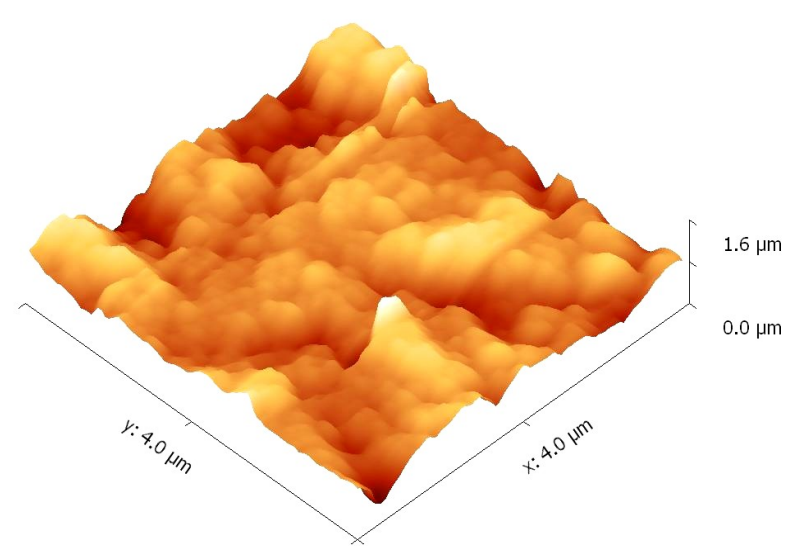

b)

Fig. 1. Raman spectrum of $\mathrm{TiO}_{2}$ nanostructures (a), AFM image of the surface of $\mathrm{TiO}_{2}$ nanostructures (b).

Raman spectrum of $\mathrm{TiO}_{2}$ nanostructures which were deposited on glass substrates, $\left(\right.$ glass $\left./ \mathrm{TiO}_{2}\right)$ is shown in figure 1a. In this spectrum the peaks at 392, 512 and $634 \mathrm{~cm}^{-1}$, which respectively correspond to $\mathrm{B}_{1 \mathrm{~g}}, \mathrm{~A}_{1 \mathrm{~g}}$ and $\mathrm{E}_{\mathrm{g}}$ modes of anatase phase of $\mathrm{TiO}_{2}$, are observed .

During the next experiment the surface morphology of deposited samples was investigated with AFM/SEM technique (Fig. 1b). The obtained $\mathrm{TiO}_{2}$ nanostructure layers had high active surface area. Mean square surface roughness (RMS), measured with software Gwiddion, was $140 \mathrm{~nm}$ for prepared $\mathrm{TiO}_{2}$ nanostructures.

PL spectra of $\mathrm{TiO}_{2}$ showed wide emission band, centered at $472 \mathrm{~nm}$ (Fig. 2). Gaussian fitting of the PL spectrum in Origin 7.0 showed two peaks, which were centered at 461 and 502 
$\mathrm{nm}$. The emission at $461 \mathrm{~nm}$ is caused by self trapped excitons and the peak at $502 \mathrm{~nm}$ is observed due to the emission from oxygen vacancies .

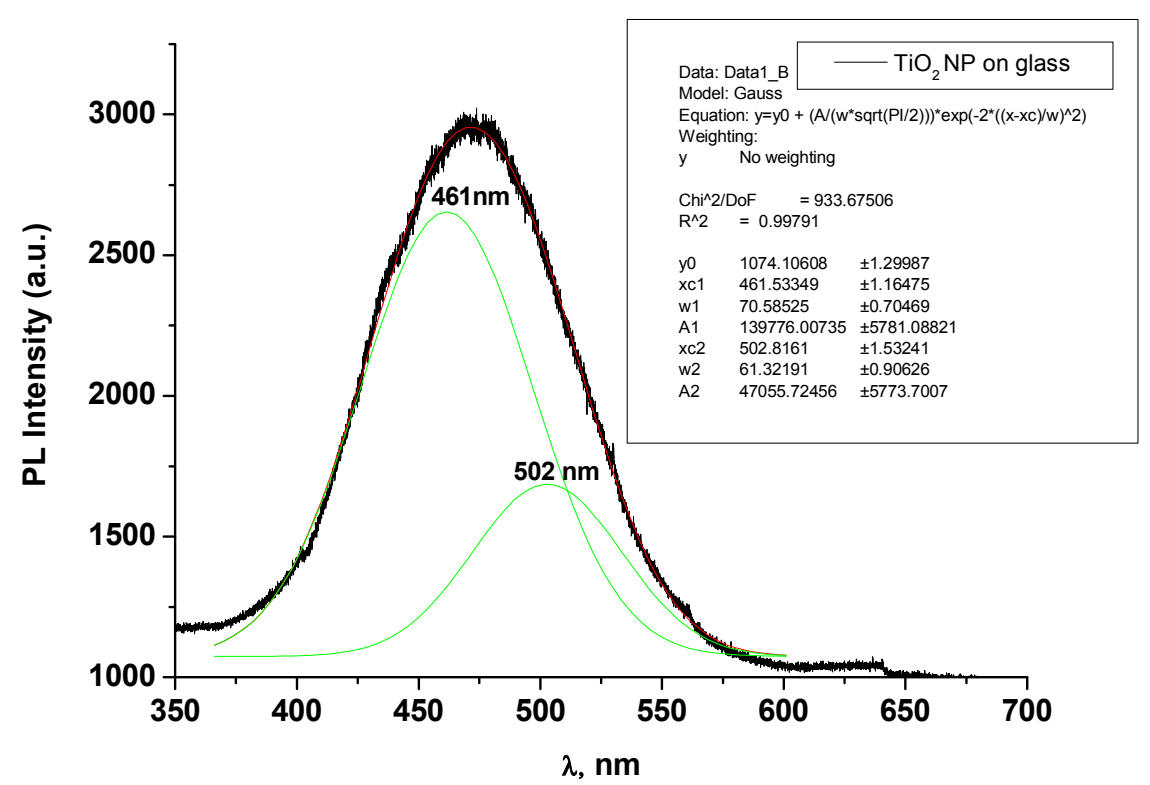

Fig. 2. PL spectrum of glass/ $/ \mathrm{TiO}_{2}$ structure excited by $266 \mathrm{~nm}$ laser.

\subsection{Effectiveness of immobilization of anti-S-Ab on the surface of glass $/ \mathrm{TiO}_{2}$ nanostructures}

Effectiveness of immobilization plays an important role in the biosensor response towards the analyte. The structure of immobilized layer determines the number of active sites that are able to interact with a target analyte .

Anti-Salmonella antibodies (anti-S-Ab) were deposited on the surface of glass $/ \mathrm{TiO}_{2}$ from solutions containing different concentrations of anti-S-Ab. After the immobilization of anti-S$\mathrm{Ab}, \mathrm{PL}$ measurements of glass $/ \mathrm{TiO}_{2} / \mathrm{anti}-\mathrm{S}-\mathrm{Ab}$ structures were performed. It was found, that the immobilization of glass $/ \mathrm{TiO}_{2}$ led to an increase of the PL intensity and IR shift of the peak positions for all studied concentrations of anti-S-Ab (Fig. 3). The obtained results are summarized in figure 4 , which shows the changes of both peak positions and PL intensity after incubation of glass $/ \mathrm{TiO}_{2}$ in solutions containing different concentrations of anti-S-Ab. At the lowest anti-S-Ab concentrations (1:200 and 1:100) drastic changes in PL intensity were observed. The saturation of PL intensity, caused by anti-S-Ab immobilization, was observed after incubation in the samples with the highest concentrations of anti-S-Ab (using 1:50 and 1:10 diluted initial sample of anti-S-Ab). The most significant PL intensity changes $v s$ concentration of anti-S-Ab were observed after the incubation of glass $/ \mathrm{TiO}_{2}$ in 1:100 diluted initial sample of anti-S-Ab. 
The shift of the PL peak position increased from 4 to $8 \mathrm{~nm}$ after incubation of glass $/ \mathrm{TiO}_{2}$ in lower concentrations of anti-S-Ab and this effect become saturated after incubation in higher concentrations of anti-S-Ab.

Incubation of glass $/ \mathrm{TiO}_{2} /$ anti-S-Ab structures in $1 \mathrm{mg} / \mathrm{ml}$ solution of BSA resulted in the increase of the PL intensity for all studied glass/TiO $/$ anti-S-Ab/BSA samples (Fig. 3).

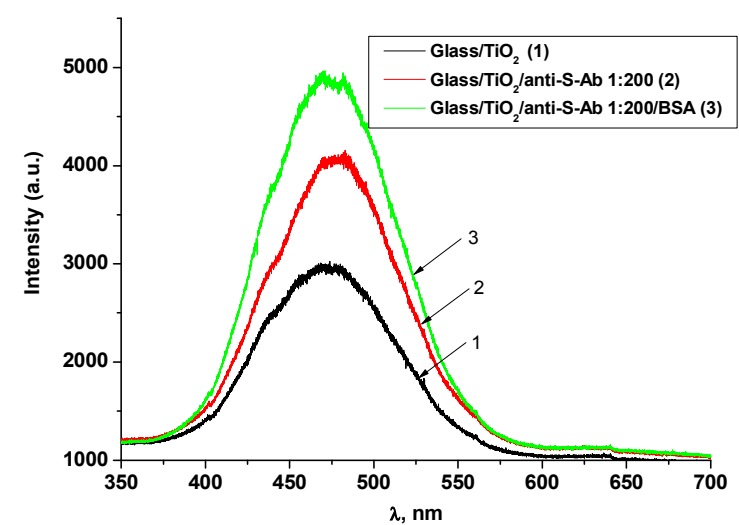

a)

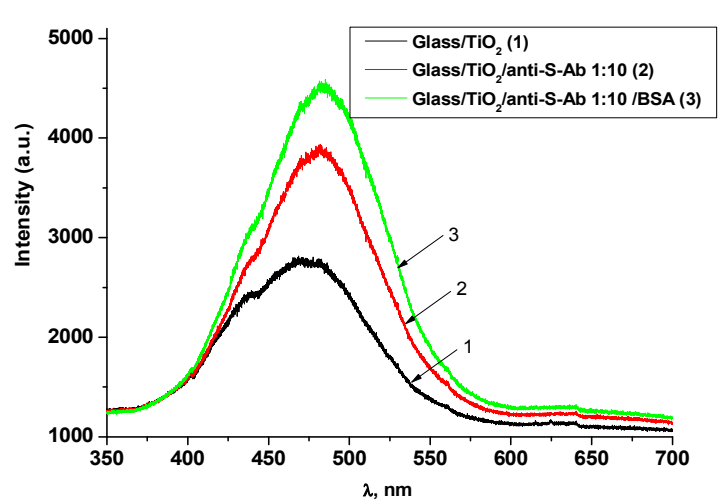

b)

Fig. 3. PL spectra of glass $/ \mathrm{TiO}_{2}$ structure before and after the immobilization of anti-S-Ab and incubation in $1 \mathrm{mg} / \mathrm{ml}$ BSA solution: a) glass $/ \mathrm{TiO}_{2}$ structure incubated in 1:200 diluted initial sample of anti-S-Ab, b) glass $/ \mathrm{TiO}_{2}$ structure incubated in 1:10 diluted initial sample of anti-S$\mathrm{Ab}$.

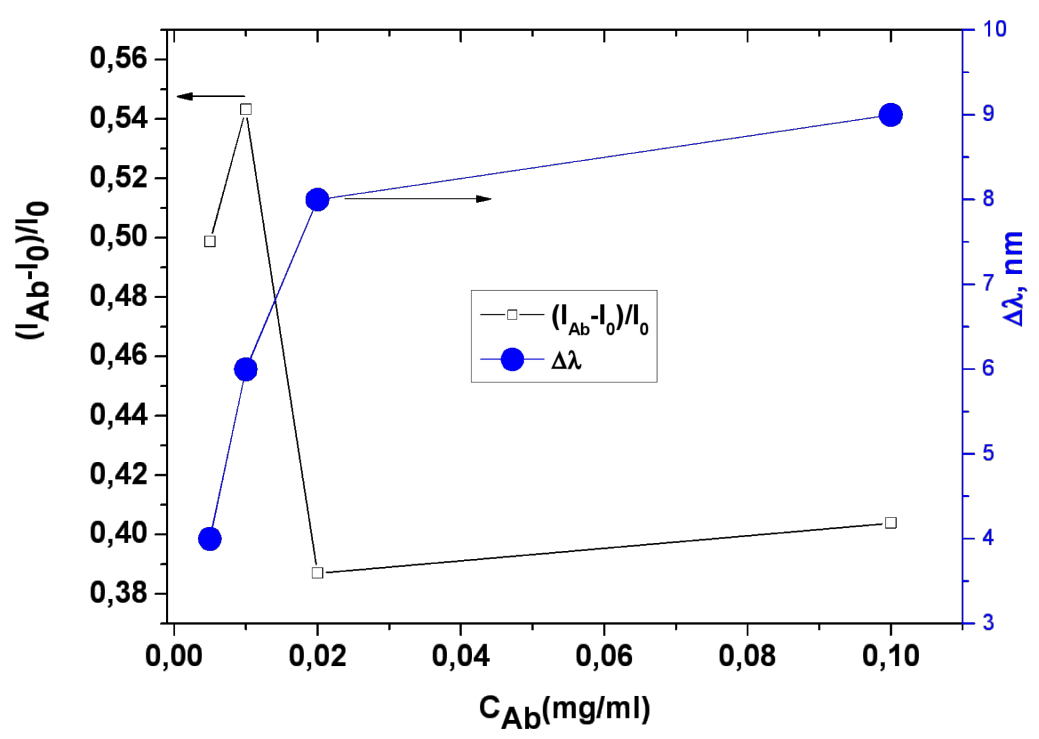

Fig. 4. The changes of glass $/ \mathrm{TiO}_{2}$ spectra after the immobilization of anti-S-Ab from solutions containing different concentrations of anti-S-Ab.

\subsection{Sensitivity of glass/ $/ \mathrm{TiO}_{2} /$ anti-S-Ab/BSA structures to Salmonella-Ag}


Glass $/ \mathrm{TiO}_{2} /$ anti-S-Ab/BSA structures were incubated in Salmonella-Ag solutions with concentrations of $10^{3}-10^{6} \mathrm{cell} / \mathrm{s} / \mathrm{ml}(\mathrm{cl} / \mathrm{ml})$ (Fig. 65). A decrease of the PL intensity of glass $/ \mathrm{TiO}_{2} /$ anti-S-Ab/BSA structures was observed after the incubation in Salmonella-Ag sample due to the formation of immune complex between antigens and antibodies. It was found that the PL spectra did not change after the incubation of glass/ $\mathrm{TiO}_{2} / \mathrm{anti}-\mathrm{S}-\mathrm{Ab} / \mathrm{BSA}$ structures in Salmonella-Ag solutions of $10^{4}-10^{5} \mathrm{cl} / \mathrm{ml}$ for structures with analyte-sensitive layers (anti-S$\mathrm{Ab} / \mathrm{BSA}$ ), formed from highest applied concentrations of anti-S-Ab. The hyperbolic function of the PL signal vs concentration of analyte is related to the 'saturation' of the bio-recognition layer by analyte at their higher concentrations .

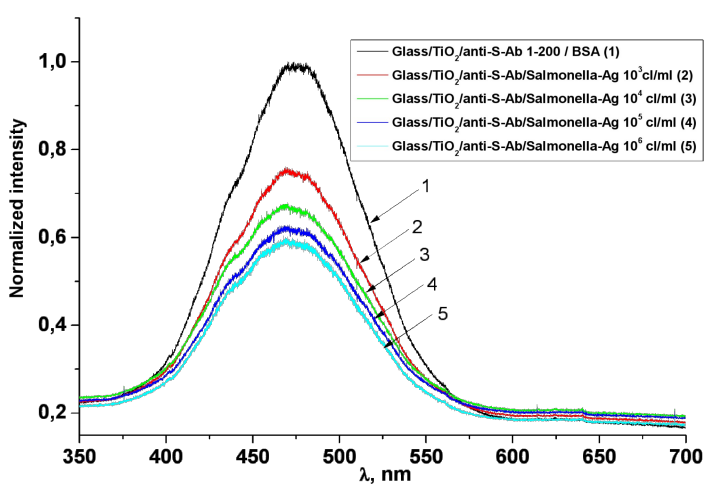

a)

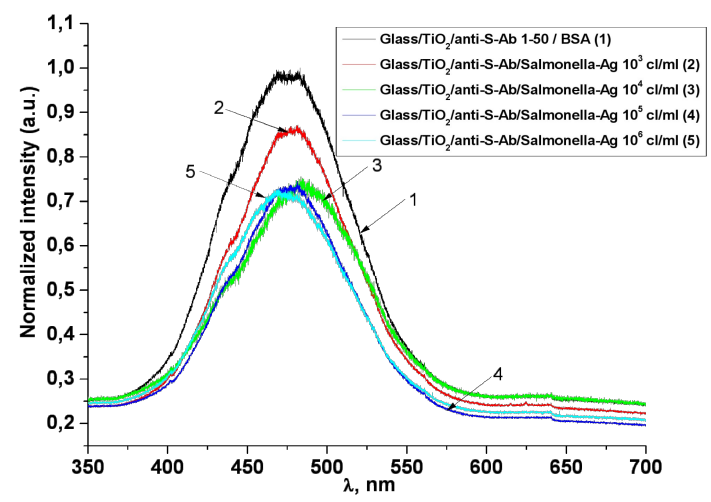

c)

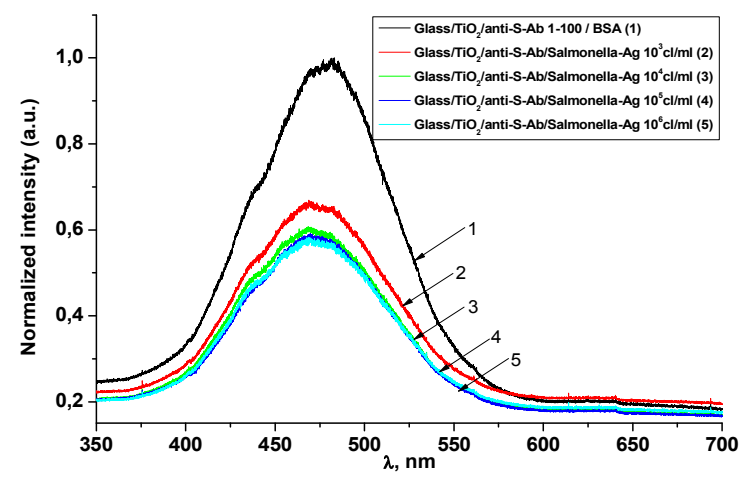

b)

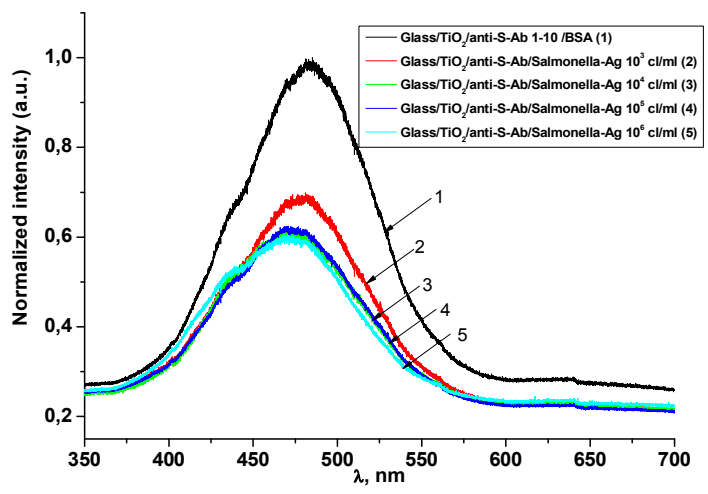

d)

Fig. 5. PL spectra during the determination of Salmonella-Ag by glass/ $/ \mathrm{TiO}_{2} / \mathrm{anti}-\mathrm{S}-\mathrm{Ab} / \mathrm{BSA}$ based immunosensor.

Procedures applied for the determination of Salmonella antigens by glass/ $\mathrm{TiO}_{2} / \mathrm{anti}-\mathrm{S}-\mathrm{Ab} / \mathrm{BSA}-$ based immunosensor consist of incubation in Salmonella antigens containing solution (20 min), 
washing out of unbounded interfering materials (3-6 min.) and the PL-measurement (1 min.). These procedures all together last less than $30 \mathrm{~min}$.

3.3. Mechanism of PL signal evolution of glass/TiO $\mathrm{O}_{2} /$ anti-S-Ab/BSA structure responce to Salmonella- $\mathrm{Ag}$

Results of sensitivity tests to Salmonella-Ag were analyzed for $\mathrm{TiO}_{2}$ samples with glass/ $\mathrm{TiO}_{2} /$ anti-S-Ab/BSA-based biosensitive layers, formed from 1:200 dissolved initial samples of anti-S-Ab (Fig. 6a). The sensitivity was calculated according to the formula:

$S=\frac{I_{0}-I_{1}}{I_{0}}$

where $I_{0}$ and $I_{1}$ are $\mathrm{PL}$ intensities of glass/ $/ \mathrm{TiO}_{2} /$ anti-S-Ab/BSA structure at peak positions registered before $\left(I_{0}\right)$ and after $\left(I_{1}\right)$ incubation in Salmonella-Ag containing solution. The sensitivity of $\mathrm{TiO}_{2}$ biosensor has a linear slope in semi-logarithmic scale in the range of $10^{3}-10^{5}$ $\mathrm{cl} / \mathrm{ml}$

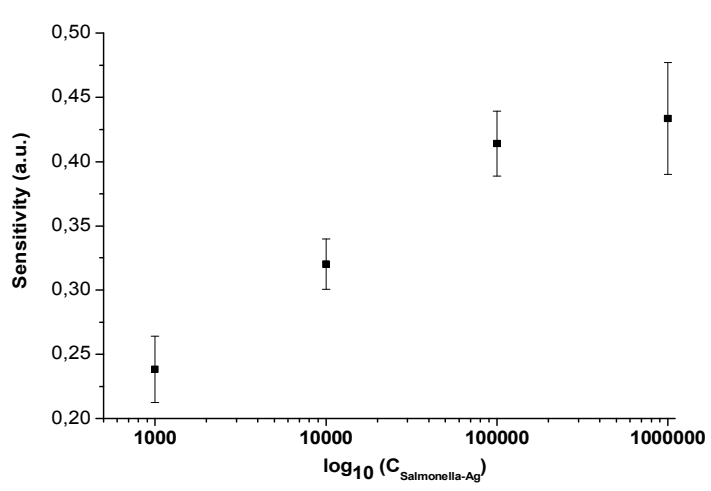

a)

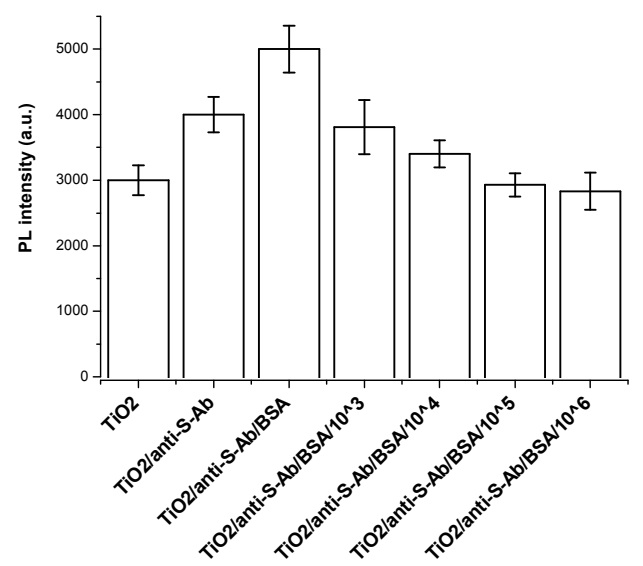

c)

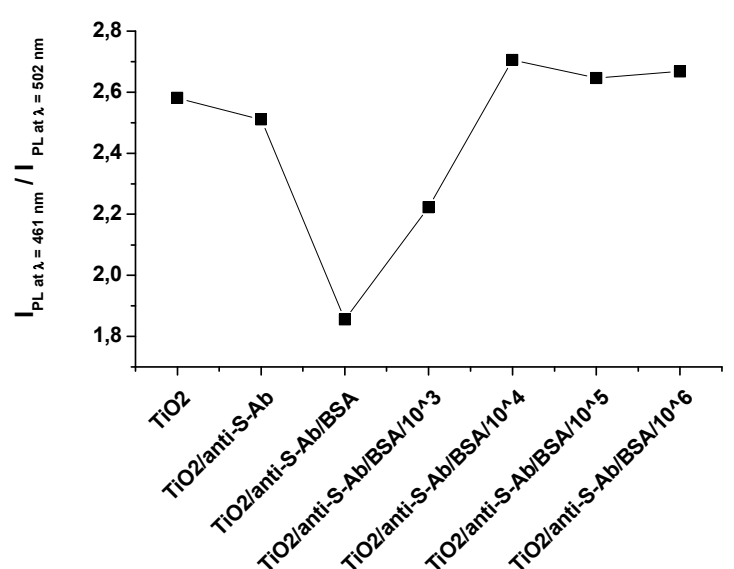

b)

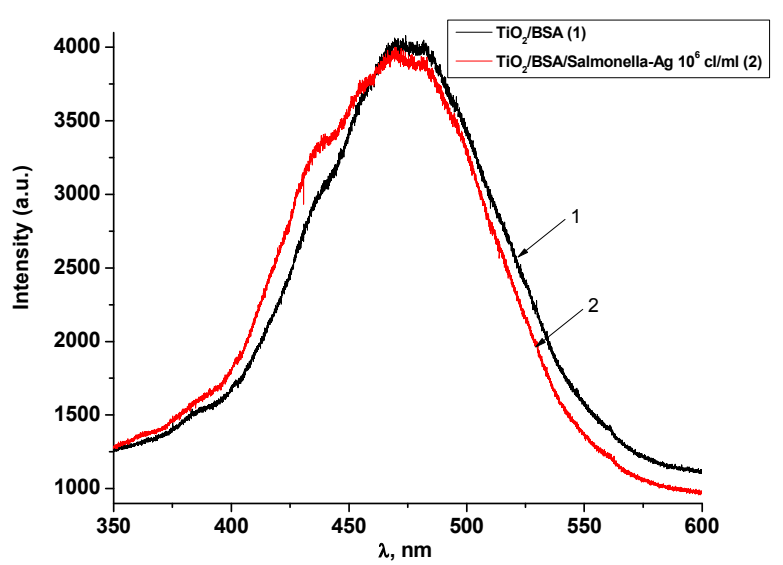

d) 
Fig. 6. Sensitivity of glass/ $/ \mathrm{TiO}_{2} /$ anti-S-Ab/BSA structure formed using 1:200 diluted anti-S-Ab towards Salmonella-Ag (a), ratio of $\mathrm{I}_{\mathrm{STE}} / \mathrm{I}_{\mathrm{V}[\mathrm{O}]}$ after each step of bio-functionalization and sensitivity tests after incubation of $\mathrm{TiO}_{2} /$ anti-S-Ab/BSA in solution containing Salmonella antigens at concentrations of $10^{3}, 10^{4}, 10^{5}, 10^{6}$ cells $/ \mathrm{ml}$, respectively: $\mathrm{TiO}_{2} /$ anti-S-Ab/BSA/Ag-

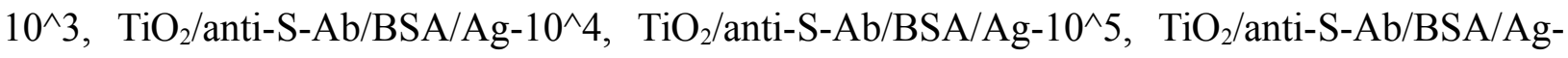
$10^{\wedge} 6(\mathrm{~b})$, average values of PL intensity at PL maximum $(\lambda=471 \mathrm{~nm})$ of $\mathrm{TiO}_{2}$ nanostructures after each step of bio-functionalization and sensitivity tests after incubation of $\mathrm{TiO}_{2} / \mathrm{anti-S}-\mathrm{Ab} / \mathrm{BSA}$ in solution containing Salmonella antigens at concentrations of $10^{3}, 10^{4}, 10^{5}, 10^{6}$ cells $/ \mathrm{ml}$ (c), PL signals of glass $/ \mathrm{TiO}_{2} /$ anti-S-Ab and glass $/ \mathrm{TiO}_{2} /$ anti-S-Ab/BSA structures after the incubation in Salmonella-Ag sample containing $10^{6} \mathrm{cl} / \mathrm{ml}(\mathrm{d})$.

As it was shown before, the PL spectrum of glass $/ \mathrm{TiO}_{2}$ structure can be divided into two spectra with corresponding peaks. These spectra are related to PL induced by recombination of: (i) self trapped excitons (STE) and (ii) oxygen vacancies. We performed the fitting of PL spectra of glass $/ \mathrm{TiO}_{2}$ structure before and after interaction with anti-S-Ab, BSA and Salmonella-Ag (the fitting is not shown here) and plotted the ratio on PL intensities related to STE and oxygen vacancies (Fig. 6b).

After the immobilization of Salmonella-Ab, which was followed by BSA adsorption, the $\mathrm{PL}$ intensity of glass/ $\mathrm{TiO}_{2} /$ anti-S-Ab/BSA induced by oxygen vacancies has increased in comparison to that of glass $/ \mathrm{TiO}_{2} /$ anti-S-Ab, what could be chosen (or induced) by several reasons: (i) the decrease of recombination of excitons (ii) charge transfer or (iii) electrostatic interaction. The formation of anti-S-Ab/Salmonella-Ab-based immune-complex was assisted by the decrease of PL mode, which was related to oxygen vacancies and the ratio of $\mathrm{I}_{\mathrm{STE}} / \mathrm{I}_{\mathrm{V}[\mathrm{O}]}$ reached the saturation at high concentrations of Salmonella-Ag.

The stability (repeatability) of the obtained immunosensor has been evaluated and shown in figure $6 \mathrm{c}$ that represents the statistics data of all immunosensor tests. The tests were performed for $7 \mathrm{TiO}_{2}$ samples. The average values of PL intensity after each step of bio-functionalization of $\mathrm{TiO}_{2}$ nanoparticles and sensitivity tests of glass/TiO $/$ anti-S-Ab/BSA structure to Salmonella antigens have been calculated as the standard deviation between number of different measurements. The studied samples showed almost similar sensitivity towards anti-Salmonella antibodies, BSA and target Salmonella antigens molecules. Some deviations were observed due to the unsignificant variations in the surface area of $\mathrm{TiO}_{2}$, which may influence a surface-density of immobilized proteins and/or some other variations of here applied analytical system. 
Supplementary PL-based test was performed in order to evaluate the specificity of the glass/ $\mathrm{TiO}_{2}$ /anti-S-Ab structure (Fig. 6d). It was found that after BSA deposition no drastic differences were observed in the PL spectra of glass $/ \mathrm{TiO}_{2} / \mathrm{BSA}$ and glass $/ \mathrm{TiO}_{2} / \mathrm{BSA} / \mathrm{Salmonella-}$ $\mathrm{Ag}$ structures. Significant changes in PL signals of glass $/ \mathrm{TiO}_{2} / \mathrm{anti-S}-\mathrm{Ab}$ and glass $/ \mathrm{TiO}_{2} / \mathrm{anti}-\mathrm{S}-$ $\mathrm{Ab} / \mathrm{BSA}$ structures before and after incubation in solutions containing Salmonella-Ag can point to the specificity of immune interaction of antigens (Salmonella-Ag) with antibodies (anti-S-Ab), which are present in glass $/ \mathrm{TiO}_{2} /$ anti-S-Ab and glass/ $/ \mathrm{TiO}_{2} /$ anti-S-Ab/BSA structures.

Possible mechanisms of interaction between $\mathrm{TiO}_{2}$ and biological compounds, which were included in anti-S-Ab, BSA and Salmonella-Ag aliquots, could be explained by passivation of surface states, charge-transfer, electrostatic interaction and Förster energy transfer. As the anti$\mathrm{S}-\mathrm{Ab}, \mathrm{BSA}$ and Salmonella-Ag are optically transparent in the UV/Vis range of the wavelengths their optical density can be neglected. Moreover, for these compounds the charge-transfer cannot be considered because neither anti-S-Ab nor BSA are able to attend in electron transfer reactions.

The most obvious mechanism of anti-S-Ab adsorption on $\mathrm{TiO}_{2}$ is based on electrostatic interaction between the surface charge of $\mathrm{TiO}_{2}$ and the charge of anti-S-Ab proteins and van der Waals interaction. Anti-S-Ab antibodies, as all the proteins, consist of amino acids that might contain positively and/or negatively charged radicals that are determining the charge of different protein domains. The large amount of negatively charged groups such as carboxyl (-COOH), aldehyde (-CHO), hydroxyl (-OH), positively charged primary amine $\left(-\mathrm{NH}_{2}\right)$, and some other groups, which are involved into the structure of amino acids, are responsible for the partial charges $(\delta+$ and $\delta$-) of some protein domains. Naturally, the charges at least partly are compensating each other, but since the ternary structure of proteins is relatively rigid and the charged groups have only limited degree of freedom to move within the protein, in some parts of the protein some uncompensated charge on the surface and inside the protein still remains. Due to the latter effect, anti-S-Ab proteins contain some partially charged groups and domains with partial positive charge ' $\delta+$ ' and negative charge ' $\delta$-', which are more or less randomly located on the surface and inside of the protein [40], the localization of these charged groups/domains depends on the amino acid sequence $[39,40]$. The partial charge of each such group is mostly lower than the full charge of an electron $e^{-}\left(1.6 \times 10^{-19}\right)$, but anyway it allows relatively strong electrostatic interaction with oppositely charged surface domains of $\mathrm{TiO}_{2}$. Such electrostatic effects can be considered as the main reason of the interaction between $\mathrm{TiO}_{2}$ and anti-S-Ab proteins in addition to the attraction of van der Waals forces, hydrogen and disulfide bonds, etc. The $\mathrm{TiO}_{2}$ (anatase) is known as n-type semiconductor with an 'upward bending' of LUMO-, HOMO-related and even some other electron energetic levels [41] suggesting the negatively 
charged surface, consequently, the positive partial uncompensated charge of anti-S-Ab (' $\delta+$ ') interacts electrostatically with the surface charge of $\mathrm{TiO}_{2}$. Further interaction of glass $/ \mathrm{TiO}_{2} / \mathrm{anti}$ $\mathrm{S}-\mathrm{Ab} / \mathrm{BSA}$-based biosensitive layer with target analyte (Salmonella-Ag) leads to both the UVshift of PL peak positions and the decrease of PL intensity to the value that corresponds to the pristine $\mathrm{TiO}_{2}$. The latter effect is caused by the fact that during the formation of an immune complex between immobilized anti-S-Ab and Salmonella-Ag, which are present in tested aliquot, the uncompensated charges $\left(\delta\right.$ - and $\left.\delta^{+}\right)$of both proteins are involved in the electrostatic interactions between oppositely charged groups in the structures of both: Salmonella-Ag and anti-S-Ab. As a result, the part of the charged groups, which initially were involved in the interaction between the anti-S-Ab and $\mathrm{TiO}_{2}$, are compensated by the oppositely charged domains/groups of the Salmonella-Ag proteins, in such a way reducing the electrostatic influence of anti-S-Ab to PL centers on the surface of $\mathrm{TiO}_{2}$. Due to these effects significant changes in the positions and intensity of PL peaks are observed before and after incubation of glass/ $\mathrm{TiO}_{2}-$ modified surfaces in solutions containing here evaluated biological compounds (anti-S-Ab, BSA and Salmonella-Ag).

\section{Conclusions}

The photoluminescence of $\mathrm{TiO}_{2}$ nanoparticles deposited on glass substrate (glass/ $/ \mathrm{TiO}_{2}$ ) were applied for the detection of Salmonella-Ag. Glass/TiO $/$ anti-S-Ab sensitive layer was formed and applied for the detection of Salmonella-Ag. More selective biological recognition layer was formed by treatment of glass/ $\mathrm{TiO}_{2} / \mathrm{anti}-\mathrm{S}-\mathrm{Ab}$ by BSA. The optimal concentration of anti-S-Ab in a solution used for the formation of glass $/ \mathrm{TiO}_{2} /$ anti-S-Ab structure was in 1:100 diluted initial sample of anti-S-Ab. The immobilization of anti-S-Ab on the $\mathrm{TiO}_{2}$ surface resulted in the increase of PL intensity and significant IR-shift of the PL spectra of glass $/ \mathrm{TiO}_{2} /$ anti-S-Ab structure in comparison with that of glass $/ \mathrm{TiO}_{2}$ structure. The interaction of glass $/ \mathrm{TiO}_{2} /$ anti-S$\mathrm{Ab} / \mathrm{BSA}$ biological recognition layer with Salmonella-Ag resulted in the decrease of PL intensity and UV-shift of PL spectra. The sensitivity of the obtained optical biosensor is in the range from $10^{3}-10^{5} \mathrm{cl} / \mathrm{ml}$ of Salmonella-Ag. The specificity and sensitivity of glass $/ \mathrm{TiO}_{2} / \mathrm{anti}-\mathrm{S}-\mathrm{Ab} / \mathrm{BSA}-$ based immunosensor has been additionally proved by evaluation of PL of glass $/ \mathrm{TiO}_{2} / \mathrm{BSA}$ and glass $/ \mathrm{TiO}_{2} / / \mathrm{BSA} /$ Salmonella-Ag structures. It was found that after the deposition of BSA on the surface of glass $/ \mathrm{TiO}_{2}$ (formation of glass $/ \mathrm{TiO}_{2} / \mathrm{BSA}$ structure) followed by similar deposition of Salmonella-Ag (formation of glass/ $/ \mathrm{TiO}_{2} / \mathrm{BSA} /$ Salmonella-Ag structure) no drastic differences 
were observed in the PL spectra of glass $/ \mathrm{TiO}_{2} / \mathrm{BSA}$ and glass $/ \mathrm{TiO}_{2} / \mathrm{BSA} /$ Salmonella-Ag structures.

Obviously, the interaction between $\mathrm{TiO}_{2}$ and biological compounds (anti-S-Ab, BSA and Salmonella-Ag) is based on electrostatic interractions, in addition to the van der Waals forces, sulfide bonds and hydrogen bonds, which all take place during the protein adsorption on $\mathrm{TiO}_{2}$ and the formation of anti-S-Ab/Salmonella-Ag immune complex.

\section{Acknowledgments}

This work was supported by EU grant PIRSES-GA-2012-318520 "Development of nanotechnology based biosensors for agriculture", Grant no. 318520.

\section{References}

1. $\quad \mathrm{Wu}, \mathrm{M} .-\mathrm{C}$., et al., Enhanced photocatalytic activity of $\mathrm{TiO}_{2}$ nanofibers and their flexible composite films: Decomposition of organic dyes and efficient $\mathrm{H} 2$ generation from ethanol-water mixtures. Nano Research, 2011. 4(4): p. 360-369.

2. Comini, E., et al., Quasi-one dimensional metal oxide semiconductors: Preparation, characterization and application as chemical sensors. Progress in Materials Science, 2009. 54(1): p. 1-67.

3. Chen, X. and S.S. Mao, Titanium dioxide nanomaterials: synthesis, properties, modifications, and applications. Chem. Rev, 2007. 107(7): p. 2891-2959.

4. Qiu, J., S. Zhang, and H. Zhao, Recent applications of TiO 2 nanomaterials in chemical sensing in aqueous media. Sensors and actuators B: Chemical, 2011. 160(1): p. 875-890.

5. Plugaru, R., A. Cremades, and J. Piqueras, The effect of annealing in different atmospheres on the luminescence of polycrystalline TiO2. Journal of Physics: Condensed Matter, 2003. 16(2): p. S261.

6. Preclíková, J., et al., Nanocrystalline titanium dioxide films: Influence of ambient conditions on surface-and volume-related photoluminescence. Journal of Applied Physics, 2010. 108(11): p. 113502.

7. Mercado, C., et al., Photoluminescence of dense nanocrystalline titanium dioxide thin films: effect of doping and thickness and relation to gas sensing. ACS applied materials \& interfaces, 2011. 3(7): p. 2281-2288.

8. Nair, P.B., et al., Effect of RF power and sputtering pressure on the structural and optical properties of TiO 2 thin films prepared by RF magnetron sputtering. Applied Surface Science, 2011. 257(24): p. 10869-10875.

9. Li, X., et al., TiO 2 films with rich bulk oxygen vacancies prepared by electrospinning for dye-sensitized solar cells. Journal of Power Sources, 2012. 214: p. 244-250.

10. Mercado, C.C., F.J. Knorr, and J.L. McHale, Observation of charge transport in single titanium dioxide nanotubes by micro-photoluminescence imaging and spectroscopy. Acs Nano, 2012. 6(8): p. 7270-7280. 
11. Sikhwivhilu, L.M., et al., Photoluminescence and hydrogen gas-sensing properties of titanium dioxide nanostructures synthesized by hydrothermal treatments. ACS applied materials \& interfaces, 2012. 4(3): p. 1656-1665.

12. Choudhury, B., B. Borah, and A. Choudhury, Ce-Nd codoping effect on the structural and optical properties of TiO 2 nanoparticles. Materials Science and Engineering: B, 2013. 178(4): p. 239-247.

13. Tripathi, A.K., et al., Study of structural transformation in TiO 2 nanoparticles and its optical properties. Journal of Alloys and Compounds, 2013. 549: p. 114-120.

14. Choudhury, B. and A. Choudhury, Tailoring luminescence properties of TiO 2 nanoparticles by Mn doping. Journal of Luminescence, 2013. 136: p. 339-346.

15. Stevanovic, A., et al., Photoluminescence of TiO2: effect of UV light and adsorbed molecules on surface band structure. Journal of the American Chemical Society, 2011. 134(1): p. 324-332.

16. Drbohlavova, J., et al., Effect of nucleic acid and albumin on luminescence properties of deposited TiO2 quantum dots. International Journal of Electrochemical Science, 2012. 7(2): p. 1424-1432.

17. Si, P., et al., Hierarchically structured one-dimensional TiO2 for protein immobilization, direct electrochemistry, and mediator-free glucose sensing. ACS nano, 2011. 5(9): p. 7617-7626.

18. Tereshchenko, A., et al., Optical biosensors based on $\mathrm{ZnO}$ nanostructures: advantages and perspectives. A review. Sensors and Actuators B: Chemical, 2016. 229: p. 664-677.

19. Setaro, A., et al., Nanograined anatase titania-based optochemical gas detection. New Journal of Physics, 2008. 10(5): p. 053030.

20. Mun, K.-S., et al., A stable, label-free optical interferometric biosensor based on TiO2 nanotube arrays. Acs Nano, 2010. 4(4): p. 2070-2076.

21. Holford, T.R., F. Davis, and S.P. Higson, Recent trends in antibody based sensors. Biosensors and Bioelectronics, 2012. 34(1): p. 12-24.

22. Viswanathan, S., C. Rani, and J.-a.A. Ho, Electrochemical immunosensor for multiplexed detection of food-borne pathogens using nanocrystal bioconjugates and MWCNT screenprinted electrode. Talanta, 2012. 94: p. 315-319.

23. Tereshchenko, A., et al., ZnO films formed by atomic layer deposition as an optical biosensor platform for the detection of Grapevine virus A-type proteins. Biosensors and Bioelectronics, 2016. 92: p.763-769.

24. Shinde, S.B., C.B. Fernandes, and V.B. Patravale, Recent trends in in-vitro nanodiagnostics for detection of pathogens. Journal of controlled release, 2012. 159(2): p. 164-180.

25. Burris, K.P. and C.N. Stewart, Fluorescent nanoparticles: Sensing pathogens and toxins in foods and crops. Trends in food science \& technology, 2012. 28(2): p. 143-152.

26. Kuijpers, A.F. and K.A. Mooijman, Detection of Salmonella in food, feed and veterinary samples by EU laboratories. Food Research International, 2012. 45(2): p. 885-890.

27. Son, J., et al. Detection of Salmonella enteritidis using a miniature optical surface plasmon resonance biosensor. in Journal of Physics: Conference Series. 2007. IOP Publishing.

28. Ohk, S.-H. and A.K. Bhunia, Multiplex fiber optic biosensor for detection of Listeria monocytogenes, Escherichia coli O157: H7 and Salmonella enterica from ready-to-eat meat samples. Food microbiology, 2013. 33(2): p. 166-171.

29. Afonso, A.S., et al., Electrochemical detection of Salmonella using gold nanoparticles. Biosensors and Bioelectronics, 2013. 40(1): p. 121-126.

30. Viter, R., et al., Immune biosensor based on silica nanotube hydrogels for rapid biochemical diagnostics of bovine retroviral leukemia. Procedia Engineering, 2011. 25: p. 948-951. 
31. Sodzel, D., et al., Continuous sensing of hydrogen peroxide and glucose via quenching of the $U V$ and visible luminescence of $\mathrm{ZnO}$ nanoparticles. Microchimica Acta, 2015. 182(910): p. 1819-1826.

32. Ohsaka, T., F. Izumi, and Y. Fujiki, Raman spectrum of anatase, TiO2. Journal of Raman spectroscopy, 1978. 7(6): p. 321-324.

33. Nakanishi, K., T. Sakiyama, and K. Imamura, On the adsorption of proteins on solid surfaces, a common but very complicated phenomenon. Journal of Bioscience and Bioengineering, 2001. 91(3): p. 233-244.

34. Hemmersam, A.G., et al., Adsorption of fibrinogen on tantalum oxide, titanium oxide and gold studied by the QCM-D technique. Colloids and Surfaces B: Biointerfaces, 2005. 43(3): p. 208-215.

35. Luo, Y., et al., pH-dependent electrochemical behavior of proteins with different isoelectric points on the nanostructured $\mathrm{TiO} 2$ surface. Journal of Electroanalytical Chemistry, 2010. 642(2): p. 109-114.

36. Solanki, P.R., et al., Nanostructured metal oxide-based biosensors. NPG Asia Materials, 2011. 3(1): p. 17-24.

37. Fahrenkopf, N.M., et al., Direct attachment of DNA to semiconducting surfaces for biosensor applications. Journal of biotechnology, 2010. 150(3): p. 312-314.

38. Joo, J., et al., A facile and sensitive detection of pathogenic bacteria using magnetic nanoparticles and optical nanocrystal probes. Analyst, 2012. 137(16): p. 3609-3612.

39. Nelson, D.L., M.M. Cox, and A.L. Lehninger, Principles of biochemistry. New York: Worth Publishtrs Inc, 2000.

40. Anna Tempczyk, Chuck Kissinger and Ernest Villafranca of Agouron Pharmaceuticals, Catalytic Mechanism of Calcineurin Serine/Threonine Protein Phosphatase, Inc.

41. Gupta S M, Tripathi M, A review of TiO2 nanoparticles, Chinese Sci Bull June, 2011, 56: $1639-1657$ 